\title{
Preparation and characterization of niobates. Part VI: Synthesis, XRD, SEM and piezoelectric studies of potassium and barium-doped lead strontium niobates
}

\author{
K UMAKANTHAM ${ }^{\dagger}$ and G NAGESWARA RAO* \\ Department of Inorganic Chemistry and 'Department of Physics, Andhra University, \\ Visakhapatnam 530003, India
}

MS received 21 June 1997; revised 16 September 1997

\begin{abstract}
Lead niobates belong to orthorhombic symmetry and acquire tetragonal symmetry at $570 \mathrm{C}$. Some lead-based ceramic compounds have been synthesized and their structural and ferroelectric properties studied. Strontium, barium and potassium were used to reduce the transition temperature and to control the grain growth, thereby electrical properties. The transition temperature was found to decrease from $465^{\circ} \mathrm{C}$ to $282^{\circ} \mathrm{C}$ with dopants. The transition temperature was drastically reduced with the addition of barium. This can be attributed to the suitability of doping ion in determining the transition temperature and other piezoelectric constants. Powder $\mathrm{X}$-ray diffraction studies were carried out and orthorhombic symmetry was confirmed. The lattice constants were calculated through diffraction patterns. The average grain size was measured from the scanning electron microscopy (SEM) pictures taken on fractured surfaces of the samples.
\end{abstract}

Keywords. Niobates: SEM; piezoelectric properties; doping of cations; grain size; dielectric constant.

\section{Introduction}

Lead niobates, $\mathrm{PbNb}_{2} \mathrm{O}_{6}$ (PBN) belong to orthorhombic symmetry and acquire tetragonal symmetry at $570^{\circ} \mathrm{C}$. The tungsten bronze (TB) type compound is similar to the perovskite structure which consists of corner sharing $\mathrm{O}^{2-}$ octahedron with central ions having two or more charges and with radii about $0 \cdot 7 \AA$ (Umakantham et al 1994b). In general, the tungsten bronze formula can be written as

$$
\left[(\mathrm{A} 1)_{2}(\mathrm{~A} 2)_{4} \mathrm{C}_{4}\right]\left[(\mathrm{B} 1)_{2}(\mathrm{~B} 2)_{8}\right] \mathrm{O}_{30} \text {. }
$$

in which the charge and size tolerance is same as that of perovskite type in case of $\mathrm{A}$, $\mathrm{B}$ sites. The $\mathrm{C}$ site being small $(0 \cdot 5-0 \cdot 7 \AA$ radius $)$ and often being vacant, may be filled by monovalent/bivalent cations. It is also mentioned as $\mathrm{AB}_{2} \mathrm{O}_{6}$ compound and the structure is tolerant to $\mathrm{A}$ site vacancies. The $\mathrm{A} 1$ sites are surrounded by columns of $4 \mathrm{BO}_{6}$, the $\mathrm{A} 2$ sites by 5 columns of $\mathrm{BO}_{6}$ and $\mathrm{C}$ sites by 3 octahedral columns of $\mathrm{O}^{2-}$. The $\mathrm{B} 2$ octahedra are surrounded by two $\mathrm{A} 2$ sites, one $\mathrm{A} 1$ site and one $\mathrm{C}$ site, while $\mathrm{B} 1$ is surrounded by two A2 sites and two C sites (Jamieson et al 1968).

PBN is exceptional in TB type of materials, as it has its polar axis in (001) plane. The polar axis can be switched through $90^{\circ}$ as well as $180^{\circ}$, resulting in ceramics with very useful piezoelectric properties. $\mathrm{PBN}$, having TB structure with $\mathrm{mm} 2$ point group, is also isomorphic with $\mathrm{Pb}_{2} \mathrm{KNb}_{5} \mathrm{O}_{15}$ (Yamada 1973). The close resemblance between $\mathrm{PbNb}_{2} \mathrm{O}_{6}$ and alkali TB was pointed out by Francombe and Lewis (1958), using

*Author for correspondence 
powder X-ray diffraction technique. Solid solutions in PBN have been extensively studied by Subbarao $(1959,1960,1962)$. PBN with Sr dopant are very useful in ultrasonic transducer applications (Coursant et al 1986).

Hence as continuation of our earlier works (Umakantham et al 1989, 1994a, b, 1996, 1997), the following solid solutions based on lead niobates are synthesized:
(1) $\mathrm{Pb}_{0.95} \mathrm{Sr}_{0.05} \mathrm{Nb}_{2} \mathrm{O}_{6}$,
(2) $\mathrm{Pb}_{0.60} \mathrm{~K}_{0.40} \mathrm{Sr}_{0.05} \mathrm{Nb}_{2} \mathrm{O}_{6}$,
(3) $\mathrm{Pb}_{0.75} \mathrm{~K}_{0.30} \mathrm{Sr}_{0.10} \mathrm{Nb}_{2} \mathrm{O}_{6}$,
(4) $\mathrm{Pb}_{0 \cdot 60} \mathrm{~K}_{0 \cdot 10} \mathrm{Ba}_{0 \cdot 10} \mathrm{Sr}_{0 \cdot 10} \mathrm{Nb}_{2} \mathrm{O}_{6}$.

The main objective in developing these materials is to study the effect of single, double and multiple dopants on ferroelectric and piezoelectric properties. Another important effect observed with multiple cations is the observed changes in the lattice structure and average grain diameter, thereby affecting piezoelectric properties.

\section{Experimental}

\subsection{Preparation of ceramic compounds}

In general, the oxide ceramic compounds can be produced by thorough mixing of oxides or carbonates or nitrides which can be readily decomposed to oxides. The above individual oxides were taken through a solid-state reaction and the mixture was dry-ball-milled followed by wet-ball milling. In fact, mixing is accompanied by dispersion of aggregates which are always present in powder form. This was done for about $4-5 \mathrm{~h}$ to effect both mixing and dispersion. Wet mixing was carried out using methanol. After methanol is dried, dry milling was carried out to increase the reactivity of the components by damaging the crystals. The various steps are given in figure 1 .

Raw materials need to be of adequate purity, reactivity and state of subdivision. The mixtures were calcined individually and simultaneously at $900^{\circ} \mathrm{C}$ for $3 \mathrm{~h}$ in air. This is intended to give a powder which often on completion will sinter to produce the required phase and crystal size with a consistent reduction/shrinkage.

The final firing/sintering of oxides was carried out in air at $1250^{\circ} \mathrm{C}$ for $3 \mathrm{~h}$. Polyvinyl alcohol which was added as a binding agent was burned in the preliminary operation at about $600^{\circ} \mathrm{C}$ for $30 \mathrm{~min}$. The carbonaceous matter was expelled when maximum temperature was reached. A small excess (2-5\%) of $\mathrm{PbO}$ was added to compensate for the lead loss as $\mathrm{PbO}$ is volatile at high temperatures. This excess $\mathrm{PbO}$ allows formation of a thin layer of liquid between the crystals of the main phase. In this case $\mathrm{PbO}$ at high temperature evaporates from the surface where it is replaced by diffusion mechanism along the grain boundaries from the interior. As the liquid phase has lost a part of $\mathrm{PbO}$,

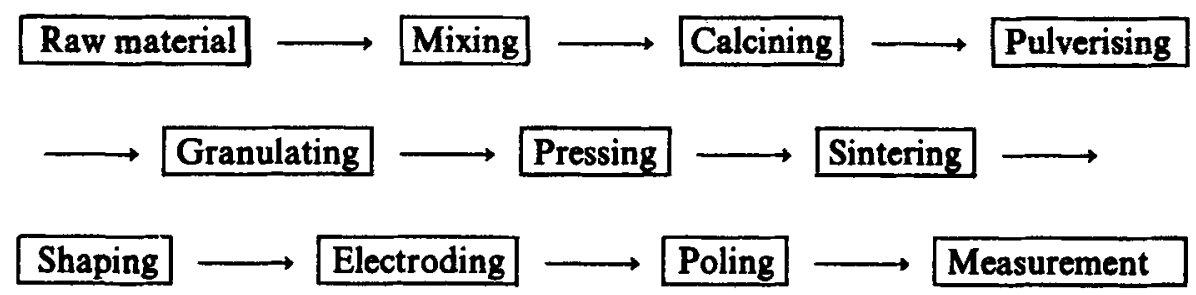

Figure 1. Flow chart of ceramic processing. 
it deposits solid on to the grains of the main phase so that a final stoichiometric, single phase dense ceramic is obtained.

After final firing/sintering the close adhesion of electrodes is important since most ferroelectrics have high dielectric constant $(\varepsilon)$ values and a large fraction of applied potential will occur across any low $\varepsilon$ gap between ceramic surface and the electrode. Therefore electrodes were formed by applying a silver paste made out of $\mathrm{Ag}_{2} \mathrm{O}$ suspension. The ceramics were then fired at $600-800^{\circ} \mathrm{C}$ in air to develop a closely adherent layer of silver on the ceramic compacts. The electroded samples were poled at $30 \mathrm{KV} \mathrm{am}^{-1}$ at $100-150^{\circ} \mathrm{C}$, which was well below the transition temperature. These samples were used for various measurements.

\subsection{Characterization}

$X$-ray diffraction spectra of all the samples were recorded at room temperature at $2 \theta$ ranging from $20-70^{\circ}$ with operating voltage and current of $25-30 \mathrm{KV}$ and $15-20$ milliamps, respectively. The Bragg angle $2 \theta$ was $1 \%$ min.

The ceramic discs were gold-coated by a thin film coating unit JFC1 100 ion sputter. The thin layer of gold coating on the surface of the ceramics avoids the electrostatic charge developed out of the ceramic surface. The SEM photographs on fractured surface of the samples were taken with JEOL SEM. SEM uses an electron beam which scans the surface of the sample causing the emission of secondary electrons suitable for viewing. A wide range of magnification upto $50,000 \times$ is possible by SEM on any surface. The average grain size was measured through the SEM pictures. The average grain diameter was calculated by linear intercept method (Umakantham et al 1996).

Dielectric measurements were made on HPLF impedance analyzer with temperature ranging from room temperature to $500^{\circ} \mathrm{C}$. The experimental technique and the dielectric cell used for the temperature variation of dielectric constant is given in detail in the paper by Umakantham et al (1994a).

The piezoelectric measurements were carried out by resonance-antiresonance technique and the constants were evaluated according to the equations given in the IRE standards. The piezoelectric strain coefficient $d_{33}$ was measured by Berlin court $d_{33}$ meter.

\section{Results and discussion}

The characterization of ceramics is essential to describe certain features of the composition and structure which are quite necessary for the investigation of various properties of ceramics (Merich and Cramel 1971).

\subsection{Lattice parameters}

Powder X-ray diffraction studies confirmed orthorhombic symmetry at room temperature for all the present samples. A typical X-ray diffraction spectrum is given in figure 2 . The diffraction patterns were analyzed and the calculated $d$ spacings and peak intensities were compared with those of lead potassium niobates, reported in JCPDS for orthorhombic tungsten bronze type niobates (JCPDS). Additional/new lines were 


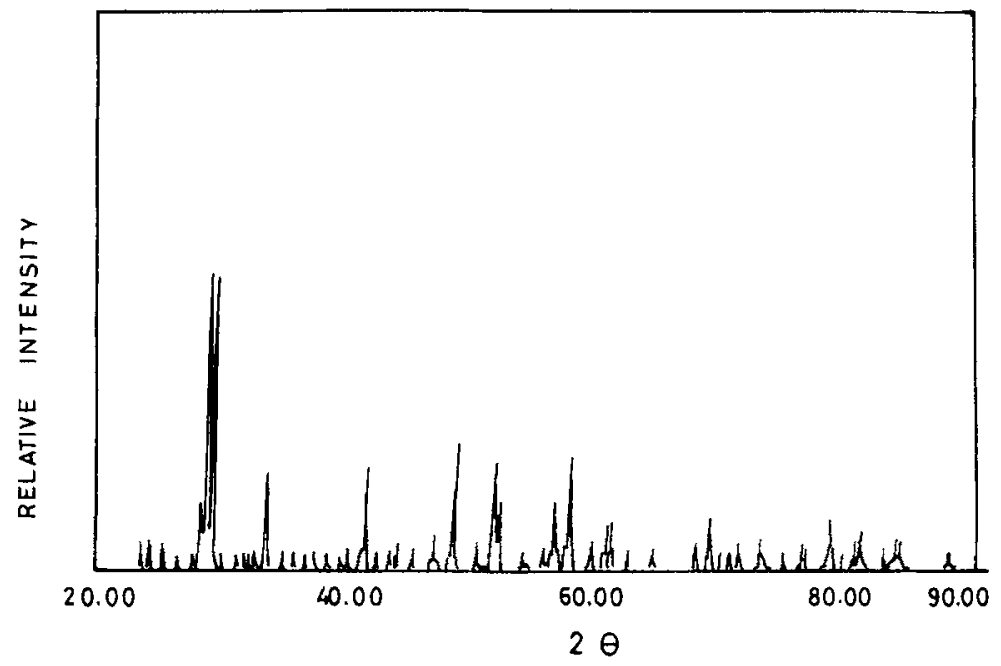

Figure 2. A typical $\mathrm{X}$-ray diffraction pattern of $\mathrm{Pb}_{0.60} \mathrm{~K}_{0.40} \mathrm{Sr}_{0.05} \mathrm{Nb}_{2} \mathrm{O}_{6}$.

Table 1. Lattice parameters and densities of some doped lead strontium niobates.

\begin{tabular}{lccccc}
\hline \multirow{3}{*}{$\begin{array}{l}\text { Sample } \\
\text { number }\end{array}$} & $\mathrm{a}(\AA)$ & $\mathrm{b}(\AA)$ & $\mathrm{c}(\AA)$ & $\begin{array}{l}\text { Axial } \\
\text { ratio }\end{array}$ & $\mathrm{a} / \mathrm{b}$ \\
\cline { 2 - 5 } 1 & 17.71 & 17.71 & 3.90 & 0.6963 & 1.0000 \\
2 & 17.76 & 17.09 & 3.94 & 0.7015 & 1.0392 \\
3 & 18.21 & 17.07 & 3.96 & 0.6876 & 1.0667 \\
4 & 18.25 & 17.02 & 3.98 & 0.6896 & 1.0723 \\
\hline
\end{tabular}

not detected in the compositions. The lattice constants $a, b$ and $c$ were calculated through diffraction patterns and the values are presented in table 1 . The lattice parameters are in agreement with the reported PKN-La by Neurgaonkar et al (1983) in similar type of compounds. Various papers have reported (Jaffe et al 1971; Yokosuka 1983) the effect of substitution at A or B sites in lead niobates by similar type of cations for improving the various properties of ceramics.

The most remarkable effect is that the c-spacing in lead strontium niobates (PSN) is only 3.90 , $a, b$ spacings are almost same and the $c$ value increases with the addition of $\mathrm{K}^{+}$and $\mathrm{Ba}^{2+}$. Regarding the a and $\mathrm{b}$ spacings in PSN (with $\mathrm{Ba}$ and $\mathrm{K}$ ), the a value increases from $17 \cdot 71$ to $18 \cdot 25$ and b value reduces from $17 \cdot 71$ to $17 \cdot 02$, which is similar to the earlier observed results in tungsten bronze type of materials (Neurgaonkar et al 1983). The ratio of a to $b$ is close to unity in all the compositions which is a characteristic nature of tungsten bronze type of materials.

There is not much change in the symmetry of $\mathrm{PbNb}_{2} \mathrm{O}_{6}$ system (Francombe 1960) of the dopants when introduced at the lower concentrations, but when multiple dopants are introduced a remarkable reduction in a value is observed with changes in $b$ values. This was attributed (Francombe and Lewis 1958) to the strong covalent bonding of $\mathrm{Pb}$ atoms with oxygen in the tetragonal site. The observed variation in the lattice constants 
is primarily due to (i) the influence of dopants (K, Ba and $\mathrm{Sr}$ ) and magnitudes of the crystal distortion, (ii) the ionic radii of the dopants, and (iii) the type of bonding preferred by $\mathrm{Pb}$ atoms with other cations in the tungsten bronze structure.

The axial ratio is essentially modified by the cations, which are in majority, and this effect could be the consequence of ordering of structure. The relatively small $c$ values and lower axial ratios of these type of materials suggest that the pluckering of $\mathrm{Nb}-\mathrm{O}-\mathrm{Nb}$ chains along the $\mathrm{c}$ axis is quite reasonable. This behaviour is also observed in other niobates (Scott et al 1968).
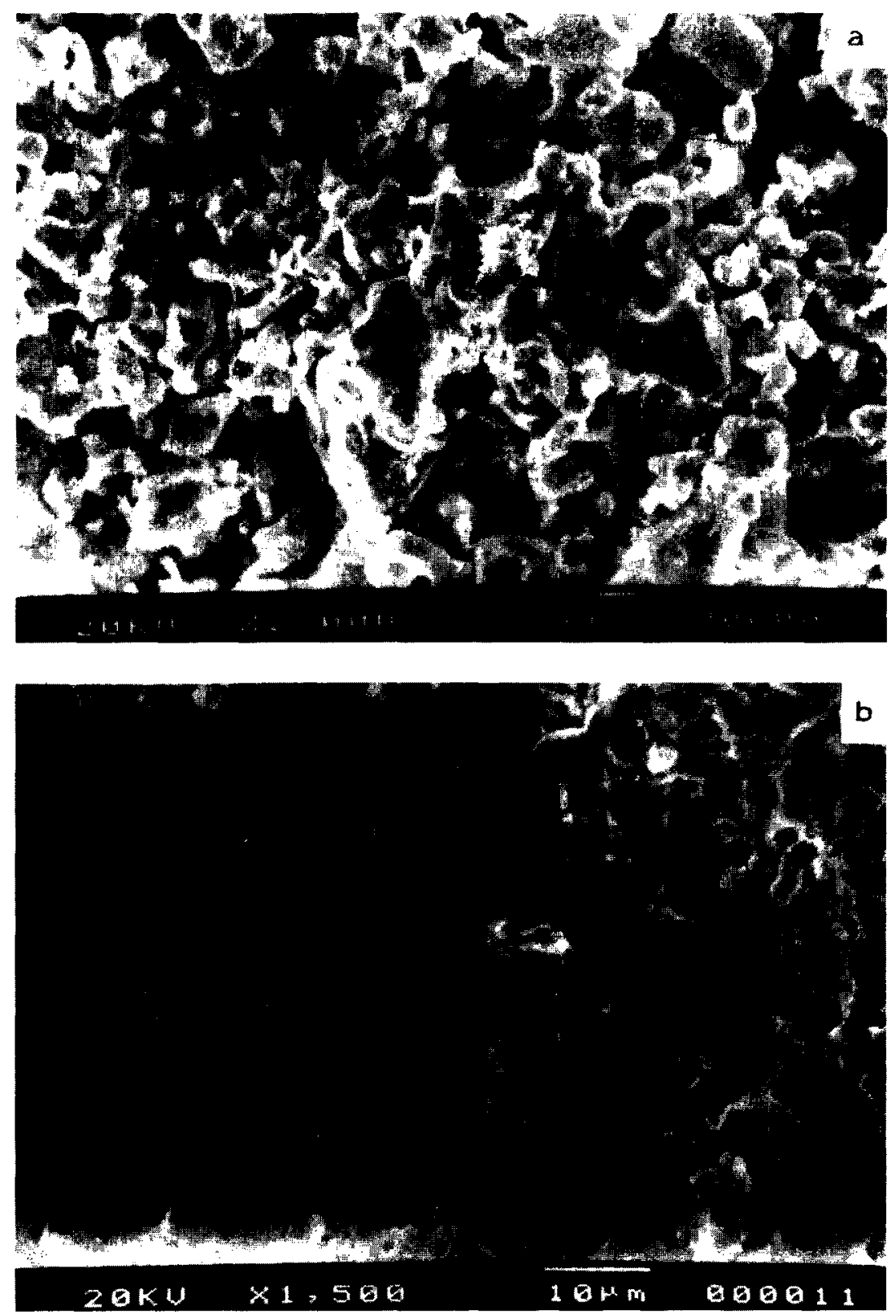

Figure 3. a- b. 

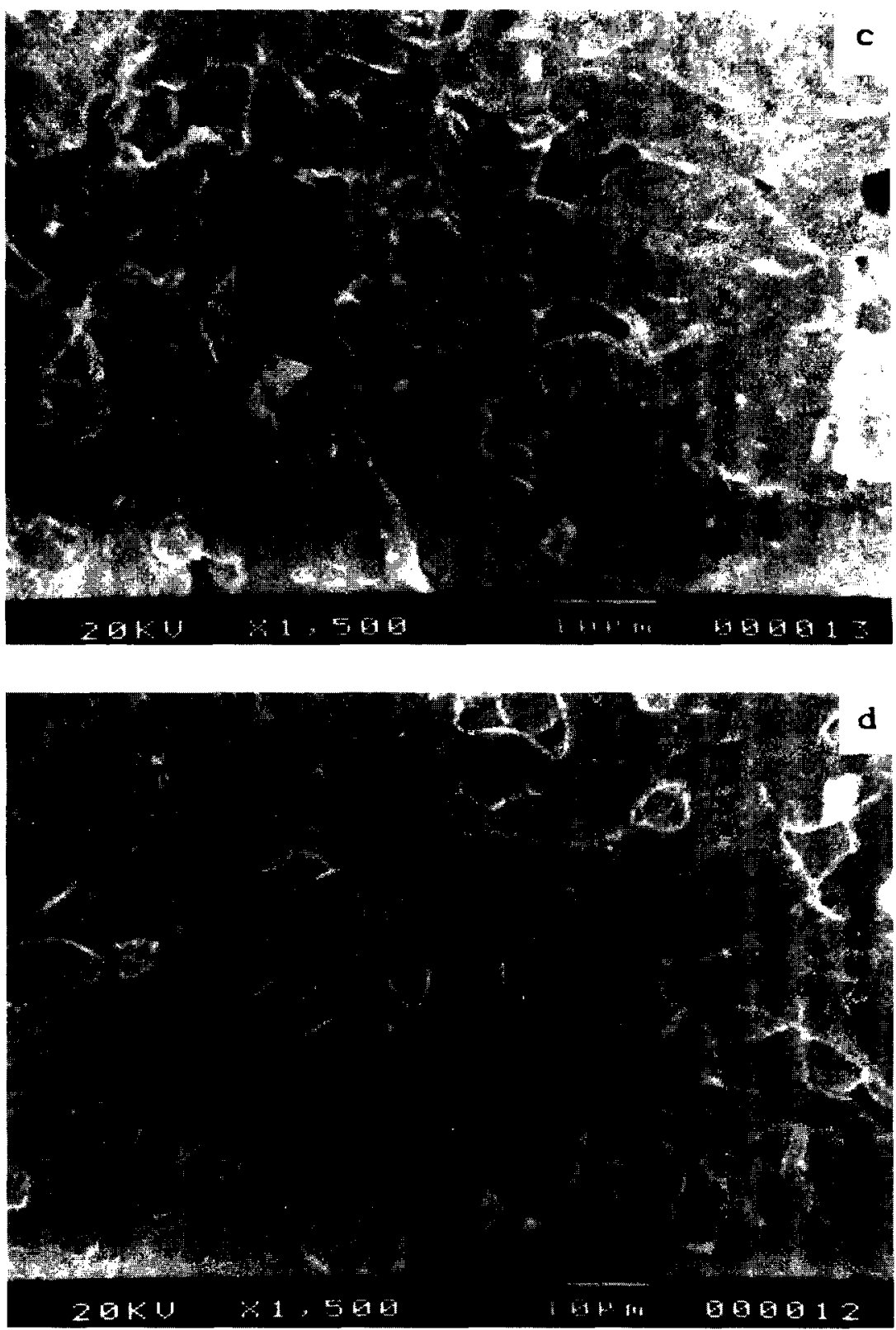

Figure 3. Scanning electron micrographs of (a) $\mathrm{Pb}_{0.95} \mathrm{Sr}_{0.05} \mathrm{Nb}_{2} \mathrm{O}_{6}$, (b) $\mathrm{Pb}_{0.60} \mathrm{~K}_{0.40} \mathrm{Sr}_{0.05}$ $\mathrm{Nb}_{2} \mathrm{O}_{6}$, (c) $\mathrm{Pb}_{0.75} \mathrm{~K}_{0.30} \mathrm{Sr}_{0 \cdot 10} \mathrm{Nb}_{2} \mathrm{O}_{6}$, and (d) $\mathrm{Pb}_{0 \cdot 60} \mathrm{~K}_{0 \cdot 10} \mathrm{Ba}_{0 \cdot 10} \mathrm{Sr}_{0 \cdot 10} \mathrm{Nb}_{2} \mathrm{O}_{6}$.

\subsection{Grain size}

Microstructure is one of the important characterizations and is also an important consideration in designing transducers, capacitors, PTC thermisters or for devices used at high voltages. So control of microstructures is necessary and this can be achieved by some methods like (i) controlling the atomic ratios, (ii) addition of selective cations 
(because grain growth is sensitive to certain additions), (iii) varying the additive concentrations, and (iv) modifying the sintering profile. The microstructure/phase distribution of the final material also depends on (i) the initial processing technique, (ii) raw materials used, (iii) phase changes due to reaction kinetics, and (iv) grain growth.

The main characteristics of microstructure that can be determined from SEM are (i) the number of identification of phases present, (ii) the relative amount of each phase present, and (iii) measurements of grain size, shape and orientation. Figure 3 gives the typical micrographs of the above ceramic compounds. The average grain diameter was found to increase with the number of dopants added. The grain growth in dense materials is associated with the grain boundary motion. Grain growth also occurs during densification of powder compacts (Lanze and Kellett 1989) as indicated by improvement in the density values. Both the densities and grain size are presented in table 2.

From the table it is clear that the grain size improved with the addition of cations, as growth behaviour is very sensitive to the cation. Some cation dopants reduce the grain growth and some cations improve the grain size by both diffusion and densification mechanism. For example, Nb inhibits grain growth (Umakantham et al 1989) and manganese (Yuhuan et al 1981) may accelerate the grain growth. Also doping increases the concentration of lattice vacancies or density by pore removal process (Coble 1962; Murray and Dhungan 1964). This depends on the distribution of charged cations and methodology of ceramic compounds.

\subsection{Variation of dielectric constant with temperature}

Dielectric constant values at room temperature and at maximum temperature and dielectric loss $(\tan \delta)$ are presented in table 2 . The transition temperature was found to decrease from $465^{\circ} \mathrm{C}$ to $282^{\circ} \mathrm{C}$ with dopants as in the case of other tungsten bronze type of materials. The transition temperature was drastically reduced with the addition of barium. Replacement of lead by barium in proportion enhances the piezoelectric activity and density and lowers the Curie temperature (Herbert 1982). This can be attributed to the suitability of doping ion in determining the transition temperature and other piezoelectric constants. The plots drawn for temperature versus dielectric constant for all the samples (figure 4) make it clear that the phase transition is sharp in all the compositions unlike the relaxors of other types of niobates (Chandramouli $e t$ al 1997).

Very high $\varepsilon$ of about $19710(\max \varepsilon)$ and low $\tan \delta$ value between 0.075 and 0.092 was observed. The dielectric constant value both at room temperature and at maximum

Table 2. Densities, grain size, dielectric constants and transition temperatures of some doped lead strontium niobates.

\begin{tabular}{|c|c|c|c|c|c|c|}
\hline $\begin{array}{l}\text { Sample } \\
\text { number }\end{array}$ & Density & $\begin{array}{l}\text { Grain size } \\
\qquad(\mu \mathrm{m})\end{array}$ & $\varepsilon_{R T}$ & $\varepsilon_{T C}$ & $T_{c}\left({ }^{\circ} \mathrm{C}\right)$ & $\begin{array}{l}\tan \delta \\
(R T)\end{array}$ \\
\hline 1 & 5.95 & 3.2544 & 745 & 16,650 & 465 & 0.083 \\
\hline 2 & 6.05 & 4.2389 & 1530 & 11,610 & 460 & 0.075 \\
\hline 3 & $6 \cdot 13$ & 6.0109 & 705 & 19,710 & 435 & 0.089 \\
\hline 4 & $6 \cdot 18$ & 6.5476 & 436 & 3,435 & 282 & 0.092 \\
\hline
\end{tabular}




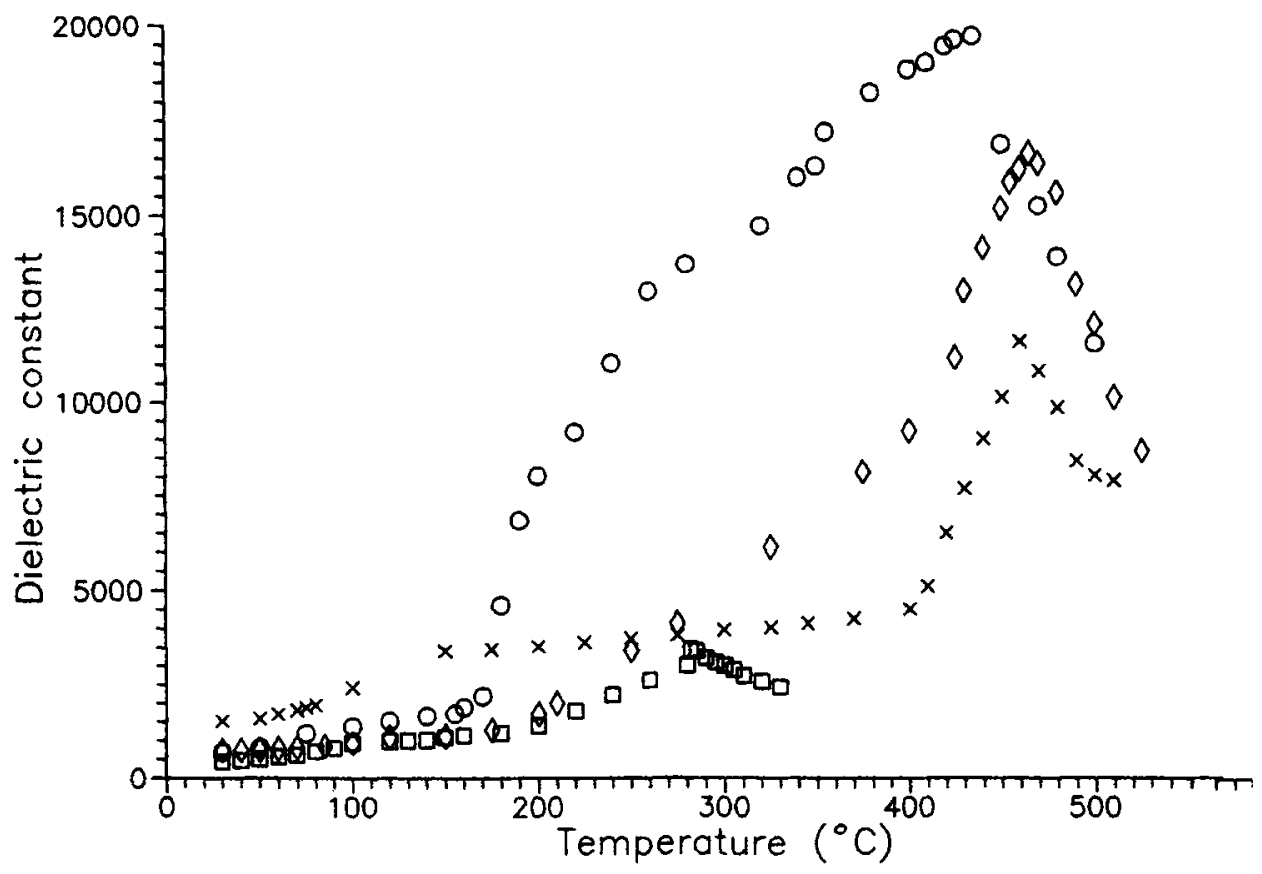

Figure 4. Variation of dielectric constant with temperature $\left(\diamond, \mathrm{Pb}_{0.95} \mathrm{Sr}_{0.05} \mathrm{Nb}_{2} \mathrm{O}_{6} ; x\right.$, $\mathrm{Pb}_{0.60} \mathrm{~K}_{0.40} \mathrm{Sr}_{0.05} \mathrm{Nb}_{2} \mathrm{O}_{6} ; \mathrm{O}, \mathrm{Pb}_{0.75} \mathrm{~K}_{0.30} \mathrm{Sr}_{0.10} \mathrm{Nb}_{2} \mathrm{O}_{6}$; $], \mathrm{Pb}_{0.60} \mathrm{~K}_{0.10} \mathrm{Ba}_{0.10} \mathrm{Sr}_{0.10} \mathrm{Nb}_{2} \mathrm{O}_{6}$ ).

temperature is also controlled when $\mathrm{Ba}$ is introduced implying stabilization as indicated by a slight broadening in transition temperature. The drastic increase in peak dielectric constant is mainly due to the introduction of both $\mathrm{Sr}^{2+}$ and $\mathrm{K}^{+}$. Similar type of behaviour was observed when $\mathrm{Ba}$ and $\mathrm{Na}$ were introduced (Jaffe et al 1971; Neurgaonkar et al 1983) in PKN as reflected by decrease in transition temperature. The decrease in transition temperature, $\varepsilon_{R T}, \varepsilon_{\max }$ with $\mathrm{Ba}$ may also be attributed to the formation of vacancies at the A site and these vacancies may be effective promoters of sintering which generally aids sintering by different mechanism. This fact was noticed by an improvement in the density by the same diffusion mechanism.

\subsection{Piezoelectric constants}

The piezoelectric strain coefficient $d_{33}$ value increases from 110 to $148 \mathrm{pc} / \mathrm{N}$ as the number of dopants are increased. The planar coupling constant $K_{\mathrm{p}}$ and thickness coupling constant $K_{\mathrm{t}}$ increase to a maximum of $32 \%$ and $34 \%$, respectively in the case of Ba-doped composition. The other coefficients like $g_{31}, d_{31}$ and frequency constant $N_{\mathrm{p}}$ do not show an uniform change with the dopants but the values coincide with the reported values. The quality factor $Q_{\mathrm{M}}$, one of the most important factors for the ultrasonic transducers, reduced from 190 to 88 with the addition of $\mathrm{Ba}$. All the piezocoefficient values are presented in table 3. Filipyev et al (1984) have also reported a low $Q_{\mathrm{M}}$ value of nearly 51 in lead niobate system with Ag doping. The lowest value of $Q_{\mathrm{M}}$ is mainly responsible for under water applications in the area of transducers. 
Table 3. Data on piezoelectric constants of some doped lead strontium niobates measured at room temperature.

\begin{tabular}{lccccccc}
\hline $\begin{array}{l}\text { Sample } \\
\text { number }\end{array}$ & $\begin{array}{c}d_{33} \\
(\mathrm{pc} / \mathrm{N})\end{array}$ & $\begin{array}{c}d_{31} \\
(\mathrm{pc} / \mathrm{N})\end{array}$ & $\begin{array}{c}g_{31} \\
(\mathrm{mv}-\mathrm{m} / \mathrm{N})\end{array}$ & $Q_{\mathrm{M}}$ & $\begin{array}{c}K_{\mathrm{p}} \\
(\%)\end{array}$ & $\begin{array}{c}K_{\mathrm{t}} \\
(\%)\end{array}$ & $\begin{array}{c}N_{\mathrm{p}} \\
(\mathrm{Hz}-\mathrm{m})\end{array}$ \\
\hline 1 & 110 & $35 \cdot 8$ & 6.02 & 190 & 23 & 19 & 2542 \\
2 & 125 & $49 \cdot 8$ & 5.95 & 150 & 26 & 28 & 2680 \\
3 & 132 & 38.5 & 9.60 & 135 & 28 & 30 & 2592 \\
4 & 148 & 34.9 & $11 \cdot 30$ & 88 & 32 & 34 & 2650 \\
\hline
\end{tabular}

In hot-pressed PKN ceramics, $K_{\mathrm{p}}$ is reported around 24\% (Nagata et al 1979) and around $32 \%$ (Filipyev et al 1984). It is also interesting that around 100 value of $Q_{\mathrm{M}}$ was observed by Nagata et al (1979). Further, highest $K_{\mathrm{p}}, K_{\mathrm{t}}$ and low $Q_{\mathrm{M}}$ was found in the same composition and this may be tailored to meet the specific needs in devices.

\section{Conclusions}

(I) X-ray diffraction studies confirmed orthorhombic symmetry for all the present samples of lead strontium niobates. The c-spacing is only $3.90, \mathrm{a}, \mathrm{b}$ spacings are almost same and the $\mathrm{c}$ value increases with the addition of $\mathrm{K}^{+}$and $\mathrm{Ba}^{2+}$. The ratio of $\mathrm{a}$ to $\mathrm{b}$ is close to unity in all the compositions, which is a characteristic nature of tungsten bronze type of materials. The relatively small $c$ values and lower axial ratios suggest that the pluckering of $\mathrm{Nb}-\mathrm{O}-\mathrm{Nb}$ chains along the $\mathrm{c}$ axis is quite probable.

(II) The average grain diameter increased with the number dopants.

(III) The transition temperature decreases from $465^{\circ} \mathrm{C}$ to $282^{\circ} \mathrm{C}$ with dopants. The transition temperature was drastically reduced with the addition of barium.

(IV) The dielectric constant value, both at room temperature and at maximum temperature, is controlled when $\mathrm{Ba}$ is introduced, implying stabilization as indicated by a slight broadening in transition temperature. The drastic increase in peak dielectric constant is mainly due to the introduction of both $\mathrm{Sr}^{2+}$ and $\mathrm{K}^{+}$.

(V) Replacement of lead by barium in proportion enhanced the piezoelectric activity and density and lowered the Curie temperature, making the present ceramics useful in under-water applications in the area of transducers.

\section{Acknowledgement}

The first author (KUM) acknowledges CSIR, New Delhi for awarding Pool Officership, 1995.

\section{References}

Chandramouli K, Umakantham K, Nageswara Rao G and Bhanumathi A 1997 Indian J. Pure Appl. Phys. 3552

Coble R L 1962 J. Am. Ceram. Soc. 45123

Coursant R H, Eyrad P, Eyrad L, Fink M and Tellier J M 1986 Proceedings 6th ISAF (New York: Gordon and Breach Science Publishers) 
Filipyev V S, Chernev Y E, Bondarenko Z V and Fesenko E G 1984 Ferroelectrics 54219

Francombe M H 1960 Acta Cryst. 13131

Francombe M H and Lewis B 1958 Acta Cryst. 11696

Herbert J M 1982 Ferroelectric transducers and sensors (New York: Gordon and Breach Science Publishers)

Jaffe B, Cok W R Jr and Jaffe H 1971 Piezoelectric ceramics (New York: Academic Press) p. 213

Jamieson P B, Abrahams S C and Bernsteen J L 1968 J. Chem. Phys. 485048

JCPDS-33-10208A, Joint committee on Powder Diffraction Standards, Garden and Carthy, Pen State University, USA

Lanze F F and Kellett B J 1989 J. Am. Ceram. Soc. 72735

Merich L L and Cramel R W (eds) 1971 Characterization of ceramics (New York: Marcel Dekker Inc.)

Murray P and Dhungan R H 1964 Ceram. Ind. 8274

Nagata K, Yamazaki T and Okazaki K 1979 Proc. second meeting ferroelectric materials and their applications (New York: Gordon and Breach Science Publishers) F-10 p. 251

Neurgaonkar R R, Oliver J R and Cary W K 1983 Mater. Res. Bull. 18735

Scott B A, Giess F A, Burus G and Kane D F O 1968 Mater. Res. Bull. 3831

Subba Rao E C 1959 J. Am. Ceram. Soc. 42448

Subba Rao E C 1960 J. Am. Ceram. Soc. 43439

Subba Rao E C 1962 J. Am. Ceram. Soc. 45528

Umakantham K, Narayana Murthy S and Bhanumathi A 1989 Ferroelectrics 94291

Umakantham K, Bhanumathi A, Nageswara Rao G and Ramana K V 1994a Indian J. Pure Appl. Phys. 32756

Umakantham K, Bhanumathi A and Nageswara Rao G 1994b Bull. Pure Appl. Sci. D13 15

Umakantham K, Chandramouli K, Nageswara Rao G and Bhanumathi A 1996 Bull. Mater. Sci. 19345

Umakantham K, Chandramouli K, Nageswara Rao G and Bhanumathi A 1997a Indian J. Pure Appl. Phys. 3552

Umakantham K, Ravindra M, Chandramouli K, Nageswara Rao G and Bhanumathi A 1997b Indian J. Phys. A71 555

Yamada T 1973 Appl. Phys. Lett. 23213

Yokosuka M 1983 Proc. international meeting ferroelectric materials and their applications FMA(New York: Gordon and Breach Science Publishers) p. 43

Yuhuan X, Zhungyang L and Xiujuan Z 1981 Ferroelectrics 37615 